Linguagem em (Dis)curso, Palhoça, SC, v. 10, n. 1, p. 69-89, jan./abr. 2010

\title{
OS SIGNIFICADOS SOCIAIS CONSTRUIIDOS PELA PRIMEIRA PÁGINA DE JORNAIS MINEIROS
}

\author{
Flaviane Faria Carvalho*
}

Resumo: O presente trabalho visa analisar os significados sociais construidos pelo layout da primeira página dos jornais mineiros Estado de Minas e Super Notícia. $O$ referencial teórico adotado é o da Semiótica Social (HODGE; KRESS, 1988; JEWITT, 2009; KRESS, 2010; KRESS; VAN LEEUWEN, 1996, 2001, 2006; MACHIN, 2007), que concebe os textos a partir de uma perspectiva multimodal, abrangendo a análise de todos os recursos semióticos utilizados em um tipo de texto, a fim de que se obtenha a compreensão total do seu significado. A metodologia do trabalho é baseada no sistema de "significados composicionais", definido por Kress e van Leeuven (1996, 1998, 2006) como a forma pela qual os recursos representacionais e interativos são integrados para estruturar os elementos do layout e conferir-lhes coerência e unidade de significação, através de três sistemas inter-relacionados: "valor informacional", "saliência" $e$ "emolduramento". Os resultados da análise indicam que o layout do Estado de Minas parece oferecer uma estrutura semiótica orientada para a ampla formação dos leitores; contudo, sugere representações tendenciosas dos atores sociais pertencentes ao domínio da política. Já o layout do Super Notícia possui uma estrutura semiótica assistemática, parecendo habituar seus leitores a informações voltadas para o consumo, sexo e violencia.

Palavras-chave: Semiótica Social; multimodalidade; imprensa; primeira página.

\section{INTRODUÇÃO}

O presente trabalho consiste em um estudo-piloto relativo a minha dissertação de mestrado (CARVALHO, 2007), em que analisei os significados sociais construídos pela primeira página dos principais jornais veiculados em Minas Gerais. Neste artigo, a primeira página dos jornais Estado de Minas e Super Notícia é investigada à luz da

\footnotetext{
* Doutoranda em Linguística Aplicada pela Faculdade de Letras da Universidade de Lisboa, Portugal.Email: flavis_carvalho@yahoo.com.br.
} 
Gramática Visual ${ }^{1}$ e da abordagem multimodal, arcabouço teóricometodológico desenvolvido por Kress e van Leeuwen (1996, 1998, 2001, 2006).

Inicio a primeira seção com uma breve contextualização acerca da mídia impressa, bem como do surgimento crescente de uma comunicação pública cada vez mais multimodal, além de situar o meu objeto de estudo em um quadro teórico específico. Em seguida, apresento o arcabouço teórico-metodológico adotado, qual seja, a Semiótica Social à luz da multimodalidade, fundamentada na Linguística Sistêmico-Funcional hallidayana (HALLIDAY, 1978, 1994). Na terceira seção, trago informações sobre a motivação de escolha do corpus, o perfil dos jornais analisados, bem como os passos metodológicos seguidos na pesquisa. Na quarta seção, analiso a primeira página dos jornais Estado de Minas e Super Notícia sob a perspectiva dos "significados composicionais"2. Na quinta seção, apresento algumas considerações finais acerca do estudo realizado, enfatizando também a eficácia e a pertinência do método utilizado para a análise e interpretação da comunicação visual.

\section{IMPRENSA E MULTIMODALIDADE}

Os estudos sobre mídia impressa justificam-se por exercer um papel central na configuração das relações de poder nas sociedades modernas, ao influenciar a expressão da cultura e a formação política e social, além de afetar as atitudes e opiniões da população, construindo e reproduzindo valores e crenças (GARRET; BELL, 1998). Segundo Fowler (1991), os eventos reportados pela mídia fazem parte de uma operação complexa e artificial de seleção, guiada por interesses econômicos e políticos, o que nos permite inferir que a produção da notícia consiste em uma prática socialmente construída.

\footnotetext{
${ }^{1}$ Minha tradução de Grammar of Visual Design. Cumpre ressaltar que, até o presente momento, não foi estabelecido um consenso no âmbito acadêmico para a tradução em português das categorias de análise oferecidas pela Gramática Visual, ficando, neste caso, sob a responsabilidade da autora deste artigo a tradução dessas categorias.

${ }^{2}$ Minha tradução de meaning of composition.

CARVALHO - Os significados sociais construídos pela...
} 
Conforme argumentam Kress e van Leeuwen (1998), houve uma revolução na paisagem da comunicação pública, especialmente na primeira página dos jornais impressos. Kress e van Leeuwen (1996) explicam que, há cerca de trinta anos, o modo semiótico predominante nos jornais era o verbal, através de caracteres impressos na página. Com a consolidação e a concorrência com a mídia audiovisual, muitos desses jornais passaram a utilizar uma profusão de imagens, cores e títulos chamativos, num espaço que outrora era monocromático e uniformemente ocupado por blocos de texto, na tentativa de atrair e estimular o interesse dos seus leitores. Segundo Ferreira Júnior (2003), a apresentação visual assume um papel cada vez mais preponderante na mídia impressa, fato observado principalmente na primeira página de jornais - unidade de significação com a qual primeiro se depara o leitor.

No cenário internacional de pesquisa em análise textual de base sistêmica, Kress e van Leeuwen (1996) propõem a análise do layout da primeira página de jornais sob o viés da Semiótica Social e da Gramática Visual, método embasado na Gramática Sistêmico-Funcional hallidayana. A Semiótica Social concebe os textos de uma perspectiva multimodal, incluindo os diferentes recursos semióticos através dos quais a linguagem é realizada. Dada a referida proliferação de signos visuais nos jornais, Kress e van Leeuwen $(1996,1998,2006)$ sublinham a importância e a necessidade de se desenvolver um método de análise que permita verificar como recursos semióticos verbais (blocos de textos, estilo das fontes, etc.) e visuais (fotografias, cores, etc.) dispostos no layout da primeira página de jornal reproduzem e constroem estruturas de significados sociais.

Tendo em vista a importância do layout da primeira página de jornal na construção e reprodução de ideias e valores na sociedade, bem como a incipiência de trabalhos acadêmicos que focalizem tal objeto a partir de uma perspectiva multimodal, este estudo mostra-se relevante por colaborar com a expansão das investigações acerca da Gramática Visual e da abordagem multimodal de análise no cenário de pesquisa nacional e internacional, uma vez que visa abordar questões relacionadas à construção de significados sociais a partir do layout da primeira página de jornais brasileiros. Para o presente estudo, proponho o corpus de análise composto pela primeira página dos jornais Estado de Minas e Super Notícia, edições de 28 de março de 2006. 
Na próxima seção, será apresentado o arcabouço téorico adotado nesta pesquisa.

\section{OS SIGNIFICADOS COMPOSICIONAIS}

A Semiótica Social da comunicação visual é funcionalista por conceber que os recursos visuais são processados para realizar tipos específicos de trabalho semiótico (JEWITT; OYAMA, 2001). Essa noção decorre do trabalho de Halliday (1994), que destaca três tipos específicos de trabalho semiótico - as chamadas "metafunções" -, sempre realizadas simultaneamente, a saber: a metafunção ideacional (relacionada ao tipo de atividade em curso), a metafunção interpessoal (o tipo de relação entre os participantes), e a metafunção textual (o modo com que o texto organiza as metafunções ideacional e interpessoal).

Em sua proposta de análise de textos multimodais, Kress e van Leeuwen (1996) adotam a noção teórica hallidayana de metafunções, fazendo algumas alterações para melhor adequá-las ao modo semiótico visual. Para Kress e van Leeuwen (1996), a comunicação visual não só representa o mundo, mas também estabelece uma interação social, com ou sem o acompanhamento do texto escrito, constituindo-se, assim, em um tipo de texto reconhecível e dotado de uma unidade de sentido significativa. Nesses termos, as metafunções ideacional, interpessoal e textual passam a ser denominadas por Kress e van Leeuwen (1996, 2006) significados "representacionais" ", "interativos"4 e "composicionais", respectivamente.

Os significados representacionais são realizados (de modo concreto ou abstrato) pelos participantes (indivíduos, lugares ou coisas) descritos, e podem ser subdivididos em duas estruturas: a narrativa ${ }^{5}$, relacionada a representações e eventos; e a conceitual ${ }^{6}$, referente à representação da "essência" dos participantes, podendo ser classificacional, analítica ou simbólica ${ }^{7}$. Os significados interativos, por

\footnotetext{
${ }^{3}$ Minha tradução de representational meaning.

${ }^{4}$ Minha tradução de interactive meaning.

${ }^{5}$ Minha tradução de narrative structure.

${ }^{6}$ Minha tradução de conceptual structure.

${ }^{7}$ Minha tradução de classification, analytical e symbolic, respectivamente.

CARVALHO - Os significados sociais construídos pela...
} 
sua vez, são expressados pelo tipo de interação estabelecida entre os participantes representados, os produtores da imagem e os espectadores destas mensagens visuais, através dos seguintes recursos: o sistema do olhar, o enquadramento, e a perspectiva ${ }^{8}$.

Levando em conta que o presente estudo focaliza a análise do layout da primeira página de jornais, selecionou-se a categoria relativa aos significados composicionais: a forma pela qual os elementos do layout são integrados a fim de conferir-lhes coerência e unidade de significação, a partir de três sistemas inter-relacionados: valor informacional, saliência e emolduramento ${ }^{9}$.

O valor informacional está relacionado com a significação atribuída aos elementos em função de sua localização na página, a partir do sistema Dado-Novo (informação apresentada como já conhecida e consensual/novidade e passível de discussão, respectivamente); IdealReal (informação idealizada e de prestígio/de caráter realístico e prático, respectivamente); e Centro-Margem (informação de valor central/de valor periférico e subserviente, respectivamente).

A saliência diz respeito aos recursos empregados nos elementos da página para atrair a atenção do leitor, e se realiza por meio da disposição das informações visuais em primeiro plano; tamanho relativo; perspectiva; contrastes de tonalidade ou cor; diferenças de brilho, entre outros. Ao enfatizar alguns elementos como mais dignos de atenção do que outros, a saliência pode gerar relações de hierarquia e poder entre os elementos. Em geral, é o grau de saliência que define a trajetória de leitura da página, iniciando do elemento mais saliente e, de forma decrescente, deslocando para o menos saliente (KRESS; VAN LEEUWEN, 2006, p. 205-208).

Os recursos de emolduramento conferem diferentes graus de conexão ou desconexão entre os elementos ou grupos de elementos dispostos na página, através da ausência ou presença de linhas de emolduramento, espaços vazios entre os elementos, relações de contraste, descontinuidades de cor e brilho, continuidades ou similaridades de cor e formato visual, vetores formados pelos próprios componentes visuais, dentre outros.

\footnotetext{
${ }^{8}$ Minha tradução de gaze, size of the frame, e perspective, respectivamente.

${ }^{9}$ Minha tradução de information value, salience e framing, respectivamente.
} 
A Figura 1, indicada abaixo, sintetiza a rede de sistemas através dos quais os significados composicionais são realizados:

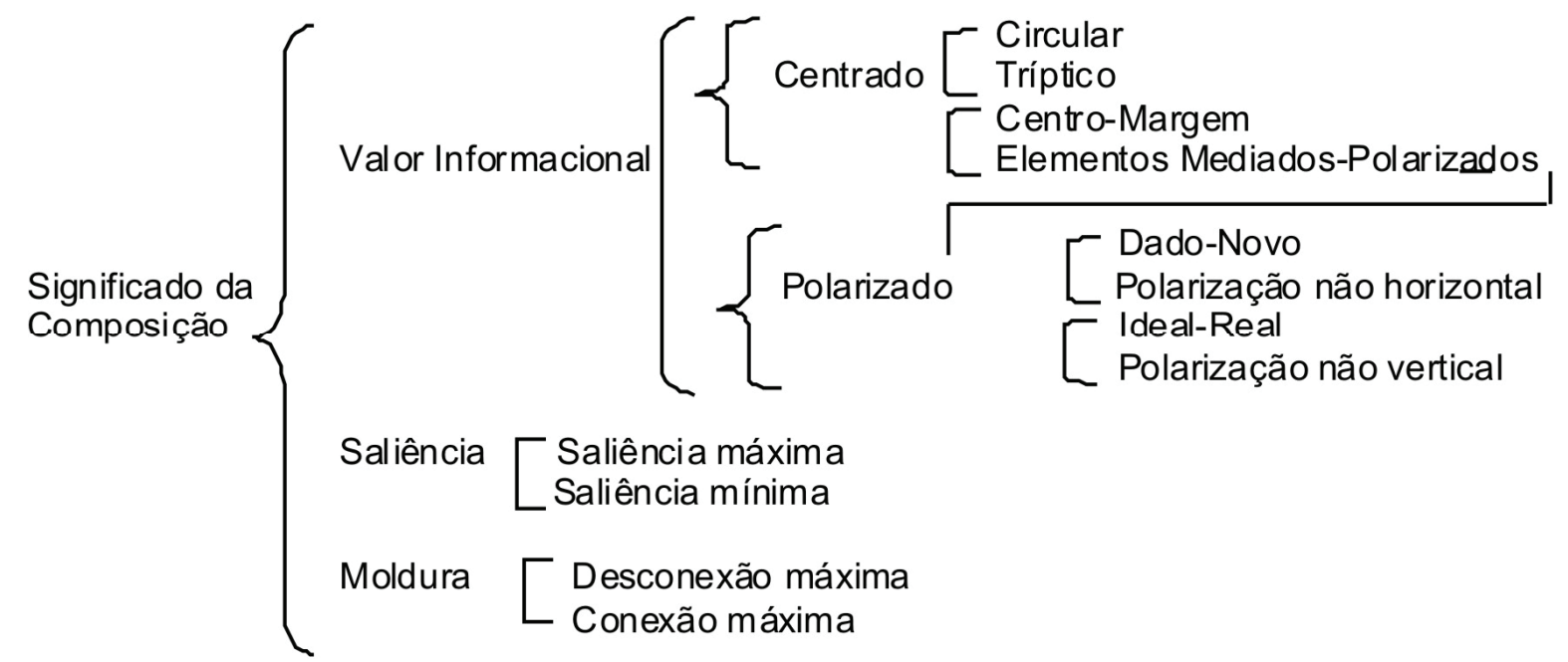

Figura 1 - Rede de sistemas concernente aos significados composicionais (adaptada de KRESS; VAN LEEUWEN, 1996, 2006).

A próxima seção informa os procedimentos metodológicos empregados neste trabalho.

\section{PROCEDIMENTOS METODOLÓGICOS}

\subsection{Corpus e motivações para sua escolha}

A opção por trabalhar com jornais impressos neste artigo deve-se a dois fatores principais. O primeiro deriva da necessidade de se expandir as pesquisas em Semiótica Social aplicadas a textos multimodais, haja vista a incipiência de trabalhos com esse enfoque no contexto brasileiro. $\mathrm{O}$ segundo fator decorre da importância indiscutível dos textos midiáticos na formação política e social da população, ao construir e reproduzir valores e crenças (BELL, 1991).

A escolha da primeira página de jornal para análise decorre do fato de esta funcionar como a porta de entrada dos leitores, atuando como a unidade de significação com a qual primeiro se deparam (FERREIRA JÚNIOR, 2003). Além disso, a atual e crescente proeminência do modo semiótico visual no layout da primeira página de jornais tem demandado, conforme argumentam Kress e van Leeuwen 
(1998), o desenvolvimento de um método de análise que possibilite compreender os significados construídos através da integração de todos os modos semióticos empregados no layout da primeira página, texto eminentemente multimodal.

Selecionado aleatoriamente para fins de estudo-piloto, o corpus é composto pela primeira página de dois jornais mineiros: Estado de Minas (formato padrão) e Super Notícia (formato tabloide), edições de 28 de março de 2006, a fim de verificar as tendências destes jornais no que tange à construção de significados sociais em suas respectivas primeiras páginas.

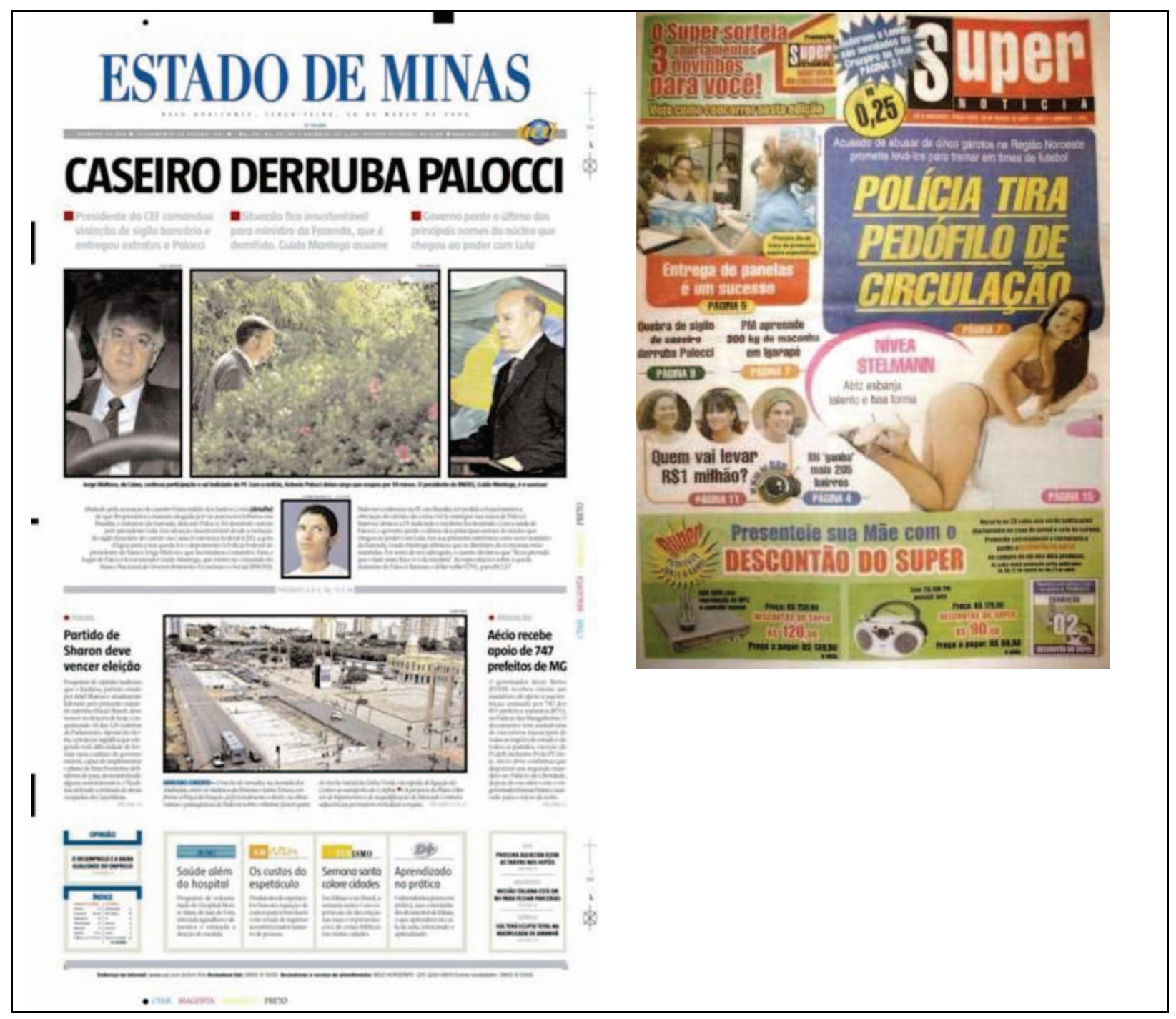

Figura 2 - Primeira página das edições de 28/03/06 dos jornais Estado de Minas e Super Notícia. 


\subsubsection{Os jornais Estado de Minas e Super Notícia}

Conforme relata Souza (2005), a trajetória do jornalismo impresso mineiro evidencia que a maioria dos seus principais veículos teve sua origem vinculada a grupos de interesse. O Estado de Minas, por exemplo, fundado em 1929, faz parte do conglomerado dos Diários Associados, grupo formado pelo famoso empresário das comunicações no Brasil, Assis Chateaubriand, que, pelo menos em Minas, sempre se posicionou favoravelmente ao governo. Com relação ao perfil dos leitores do jornal ${ }^{10}$, observa-se a predominância do público masculino (53\%), compreendendo uma faixa etária entre 20 e 29 anos (28\%), cuja classe social é a B (38\%), com uma renda mensal de até 5 salários mínimos $(30 \%)$, tendo como grau de instrução o ensino médio incompleto/completo (44\%). No que confere à tiragem ${ }^{11}$, o jornal circula diariamente e apresenta maior vendagem aos domingos (121 mil exemplares), reduzindo o índice de vendas durante os dias úteis (75 mil exemplares). Atualmente, o grupo Diários Associados possui 12 jornais, 6 emissoras de televisão, 14 rádios e 10 empresas afins, distribuídos pelo país. Destes, pode-se citar, em Minas Gerais, os seguintes veículos jornalísticos: o Estado de Minas, o Diário da Tarde (extinto em julho de 2007), o Aqui, a rádio Guarani e a TV Alterosa.

O Super Notícia, por seu turno, foi lançado em $1^{\circ}$ de maio de 2002 (Dia do Trabalho) pelo empresário e deputado federal Vittorio Medioli, também fundador do jornal $O$ Tempo, principal concorrente do Estado de Minas. Editado pela Sempre Editora ${ }^{12}$, o Super Notícia retirou a soberania do Estado de Minas (até então o jornal mais vendido de Minas Gerais), e atualmente é o terceiro jornal mais vendido do país. Apesar de ter como proprietário um deputado federal, o Super Notícia pouco aborda assuntos do âmbito político, priorizando a fórmula "crime-sexopromoção". Composto por matérias curtas, de fácil leitura, simplicidade de conteúdo, serviços de utilidade pública, e permeado de promoções, o Super atinge todas as classes sociais, principalmente as C e D.

No que tange ao perfil de seus leitores ${ }^{13}$, prevalecem no Super Notícia pessoas do sexo masculino (59\%), compreendendo uma faixa

\footnotetext{
${ }^{10}$ XLV Pesquisas Marplan Ltda. $-1^{\mathrm{o}}$ semestre de 2004.

${ }^{11}$ IVC (Instituto Verificador de Circulação) - abril de 2007.

${ }_{12}^{12}$ Sua sede é a mesma do jornal $O$ Tempo, bem como sua equipe jornalística.

${ }^{13}$ Pesquisas Marplan Ltda. $-4^{\circ}$ trimestre de 2005.

CARVALHO - Os significados sociais construídos pela...
} 
etária entre 20 a 29 anos, cuja classe predominante é a C (53\%). Para completar a receita de seu sucesso, o jornal é vendido por ambulantes a $\mathrm{R}$ \$ 0,25 , tornando-se uma boa opção para os trabalhadores que estão a caminho do serviço, e para aqueles que estão passando pela rua, parados no sinal de trânsito, ou mesmo sem tempo de ir à banca. A tiragem ${ }^{14}$ média diária do Super Notícia é de 133.938 exemplares. O jornal circula diariamente, apresentando uma queda de vendagem aos sábados (121.916 exemplares) e domingos (111.505 exemplares), se comparado aos outros dias da semana. $\mathrm{O}$ fato de o tabloide demonstrar um aumento significativo de vendas na segunda-feira (153.483 exemplares) parece indicar que, em dias úteis, junto aos locais de trabalho ou mesmo em conjunto com outros colegas, é maior o interesse pelo jornal e mais fácil a aquisição do exemplar ${ }^{15}$.

\subsection{Metodologia}

Com a finalidade de analisar os significados sociais construídos pelo layouts da primeira página dos jornais Estado de Minas e Super Notícia, foram seguidas as etapas indicadas abaixo:

1) Cada um dos textos multimodais que compõem o corpus deste estudo foi analisado a partir da categoria referente aos significados composicionais, de acordo com a proposta de Kress e van Leeuwen (1996, 2006). Nessa etapa, pretendeu-se aplicar a referida categoria ao corpus a fim de se verificar as estruturas de significados sociais representadas.

2) Os resultados observados em cada um dos textos multimodais foram discutidos de forma comparativa.

Apresentado o referencial teórico-metodológico utilizado neste trabalho, seguem na próxima seção a análise e a discussão dos dados extraídos da primeira página dos jornais em questão.

\footnotetext{
${ }^{14}$ Pesquisas Marplan Ltda. $-4^{\circ}$ trimestre de 2005.

${ }^{15}$ Departamento Comercial do Super Notícia - junho de 2006.
} 


\section{ANÁlise CONTRASTIVA DA PRIMEIRA PÁGINA DO ESTADO DE MINAS E SUPER NOTÍCIA}

\section{Valor informacional}

\section{Dado e Novo}

Na edição do Estado de Minas, o ex-ministro da Fazenda Antônio Palocci é representado através da configuração de um tríptico, ocupando a posição central, sendo assim o núcleo da informação, e cumpre o papel de mediador de elementos polarizados: no domínio do Dado, lado esquerdo da página, aparece o funcionário da Caixa Econômica, Jorge Mattoso, que incriminou o ministro ao confessar participação no crime. Nesse sentido, o funcionário é apresentado como informação dada e incontestável. Já no domínio do Novo, lado direito da página, aparece Guido Mantega, que na ocasião assumiu o cargo de Palocci. Mantega é exatamente a informação nova: sinalizando máxima saliência, sua imagem aparece carregada de cor, luminosidade e brilho, envolta por um fundo claro onde se visualiza a bandeira do Brasil, o que parece sinalizar a possibilidade de uma gestão mais transparente e comprometida com os interesses do país - informação que não deixa de estar passível de contestação.

$\mathrm{Na}$ edição analisada do Super, o valor informacional é polarizado, e o domínio do Novo constitui o destaque da página, com a foto da atriz da rede Globo Nívea Stelmann, e também com a chamada "Polícia tira pedófilo de circulação", ensejando vê-las como informações ainda não conhecidas pelo leitor e, por isso, dignas de atenção. No domínio do Dado, visualizam-se em menor saliência os concorrentes do programa também da emissora global Big Brother Brasil - Mara, Mariana e Rafael. Neste caso, configura-se um tríptico Dado/Mediador/Novo: a jovem e bela modelo Mariana ocupa uma posição central, a ex-boia fria Mara é apresentada como informação dada, familiar ao público-alvo do tabloide, cuja classe social (C) é análoga à da baiana. Rafael, por sua vez, encontra-se no domínio do Novo, como informação passível de contestação, uma vez que o público entrevistado pelo tabloide não demonstrou simpatia nem torceu para que o professor conquistasse o prêmio. 
Mas o que prevalece na composição geral do tabloide como domínio do Dado é a notícia sobre a promoção realizada pelo Super Notícia, que consiste no recorte do selo presente na primeira página do jornal a fim de obter em troca um jogo de panelas. Ao selecionar esse tipo de evento como notícia e disponibilizá-lo no campo do Dado, o tabloide enseja uma tendência que parece corromper a práxis e a ontologia do jornalismo. Se este se fundamenta em ideais calcados no compromisso social de educar e formar cidadãos reflexivos acerca dos acontecimentos do cotidiano, o que se observa é um possível apagamento de tais princípios. Nesses termos, o Super Notícia parece atuar no sentido de naturalizar entre os leitores a ideia de comprar um jornal para adquirir um "Superdesconto" na compra de panelas, ao invés de buscarem se informar e se tornar cidadãos críticos e reflexivos.

\section{Centro e Margem}

Logo abaixo do tríptico configurado no Estado de Minas aparece, em uma dimensão consideravelmente menor, o caseiro Francenildo Costa, responsável pela acusação feita a Palocci. Em uma estrutura Centro-Margem, o caseiro é representado como a informação central, porém em menor saliência, ao passo que o texto explicativo do caso Palocci cumpre uma função marginal, pois se situa à margem da referida informação central. Embora Francenildo tenha desencadeado todas as acusações sobre Palocci, o Estado de Minas atribuiu pouca relevância ao retratar o caseiro, pois priorizou a representação dos grupos políticos que estão no poder, ao elencá-los no campo do Ideal.

Já na edição analisada do tabloide Super não há representação Centro/Margem, talvez porque todos os elementos dispostos na página parecem competir pela atenção do leitor.

\section{Real e Ideal}

Conforme já observado, a edição analisada do Estado de Minas traz no domínio do Ideal, seção superior da página, a pauta política nacional, que se configura em um tríptico Dado/Mediador/Novo, atribuindo-lhe, assim, prestígio, valor e destaque. 
No campo do Real, seção inferior da página, predominam pequenos textos de diferentes editorias (cultura, saúde, voluntariado, economia, ciência), excetuando-se a notícia sobre a cobertura do rio Arrudas, cuja representação aparece em posição central e em tamanho considerável. A obra faz parte do projeto Linha Verde, via expressa a ser construída pelo Executivo estadual, ligando o centro de Belo Horizonte ao Aeroporto Internacional de Confins. O "Boulevard Arrudas", atuando como um dos braços deste projeto, visa promover a revitalização urbanística do centro da cidade, chamando, portanto, a atenção do leitor para as ações políticas de caráter local. Talvez a ênfase atribuída ao "Boulevard Arrudas" possa ser explicada pelo contexto histórico, visto que sua inauguração foi feita às vésperas da $47^{\mathrm{a}}$ Reunião Mundial do $\mathrm{BID}$, que trouxe para a cidade cerca de 7 mil banqueiros, investidores e administradores públicos.
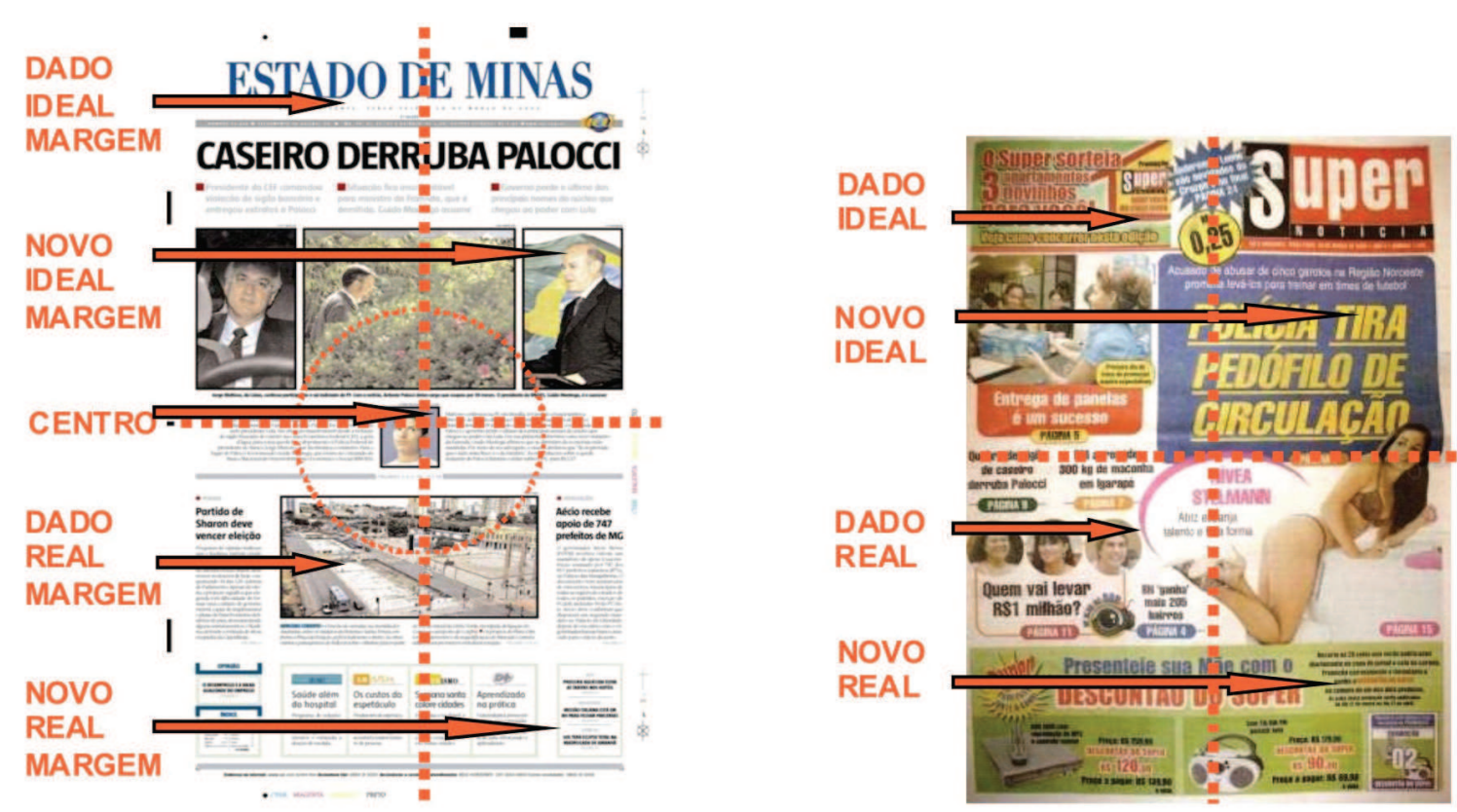

Figura 3 - Primeira página dos jornais Estado de Minas e Super Notícia - análise sob o enfoque do valor informacional.

Na edição analisada do Super, o Ideal é composto por um tríptico Dado/Mediador/Novo revelador. No que confere ao Dado, mais uma vez, nota-se a tendência por parte do tabloide de tornar a promoção de sorteios no jornal uma prática familiar ao leitor - desta vez carregada de idealização, pois ao invés de panelas, sons e dvd's, é lançada a possibilidade de se ganhar um apartamento. O logotipo do tabloide situa- 
se no campo do Novo, parecendo ressaltar a importância dada à novidade, atraindo a atenção do leitor. Cumprindo o papel de mediadores no domínio do Ideal, encontram-se o preço do tabloide $(\mathrm{R} \$ 0,25)$ e uma chamada relativa à cobertura esportiva, configuração que lhes atribui uma importância literalmente central neste domínio.

Em se tratando do domínio do Real, o factual, o que faz parte do mundo vivido pelo leitor, o que o impele à ação de comprar e consumir, resume-se, na propaganda, nos produtos e nas promoções que o tabloide tem a oferecer. O selo, inclusive, aparece no campo do Novo, em destaque para o leitor-consumidor, para que este o recorte e obtenha desconto na compra de um DVD e um aparelho de som portátil.

\section{Saliência}

Na primeira página do Estado de Minas foi idealizada e recebeu maior saliência a chamada sobre a demissão do ex-ministro da fazenda Antônio Palocci, o que pode ser observado pela sua localização no topo da página, além da cor, da precisão do foco e tamanho significativos das fotos e da fonte empregada no título da chamada ("Caseiro derruba Palocci”). A representação de sua punição, saída e apagamento do cenário político é sugerida ao mostrá-lo em segundo plano, de cabeça baixa, praticamente escondido atrás de um arbusto apresentado em primeiro plano. Ressalta-se aqui a sombra negra sobre a cabeça de Mattoso e o fundo escuro no qual se encontra, ensejando um tipo de representação depreciativa. Envolto por um cenário ausente de cor e brilho, o funcionário da Caixa parece participar de uma atmosfera de culpa e condenação.

Vale mencionar ainda que, ao representar o caseiro Francenildo Costa com uma saturação mínima e logo abaixo de Mantega, Palocci e Mattoso, o jornal parece evidenciar um tipo de representação ideológica em que o caseiro aparece menos dotado de poder e importância se comparado aos demais atores sociais representados.

Ademais, pode-se verificar também um certo grau de saliência aplicado à chamada sobre o Ribeirão Arrudas, pertencente à capital mineira Belo Horizonte, haja vista a localização central e o tamanho significativo da fotografia. 
Desta perspectiva, pode-se inferir que a edição analisada do Estado de Minas tende a sugerir como dotada de maior probabilidade a seguinte trajetória de leitura: prioriza a pauta política nacional, demarcando inclusive diferenças hegemônicas de poder e, posteriormente, destaca os eventos ligados à política e ao cotidiano do Estado mineiro.

A primeira página do tabloide Super do mesmo período apresenta um layout semelhante a um folheto de promoções de supermercado. Todos os eventos da página parecem disputar a atenção do leitor, usando de cores, imagens e letras garrafais, engendrando uma composição de máxima saliência. Com efeito, o uso da cor amarela, pano de fundo para as informações textuais referentes ao preço do jornal e às legendas das fotografias de destaque na página, parece funcionar como recurso de saliência, visto que atrai a atenção do leitor devido à intensidade de sua coloração.

A fotografia de Nívea Stelmann, atriz da TV Globo, recebe o maior grau de saliência, pois está representada em primeiro plano, com foco preciso, dotada de brilho e luminosidade, e com um tamanho relativamente maior se comparada às demais fotos da página. As representações das chamadas "Entrega de panelas é um sucesso" e "Presenteie sua Mãe com o descontão do Super" também ganham significativa saliência: a primeira por situar-se no domínio do Ideal, pela força do foco e pelo grau de luminosidade atribuído aos atores sociais que aparecem entregando as panelas aos leitores-consumidores; já a segunda por ocupar todo o domínio do Real e pela saturação de cores e tamanho de letras adotado. Por fim, a chamada "Polícia tira pedófilo de circulação" recebe considerável teor de saliência, por conta das fontes garrafais empregadas no título e por sua disposição no domínio do Ideal.

Desse modo, a edição analisada do Super Notícia parece sugerir variadas trajetórias de leitura, tendo em vista que a chamada mais saliente, relativa à representação sensual da atriz Nívea Stelmann, estabelece diferentes vetores com as demais chamadas da página, conforme ficará evidenciado na seção seguinte. Contudo, se for levado em conta as chamadas mais salientes, a trajetória de leitura mais provável seria: representação sensual de mulheres famosas, cobertura policial, e oferta promoções, sorteios e descontos. 

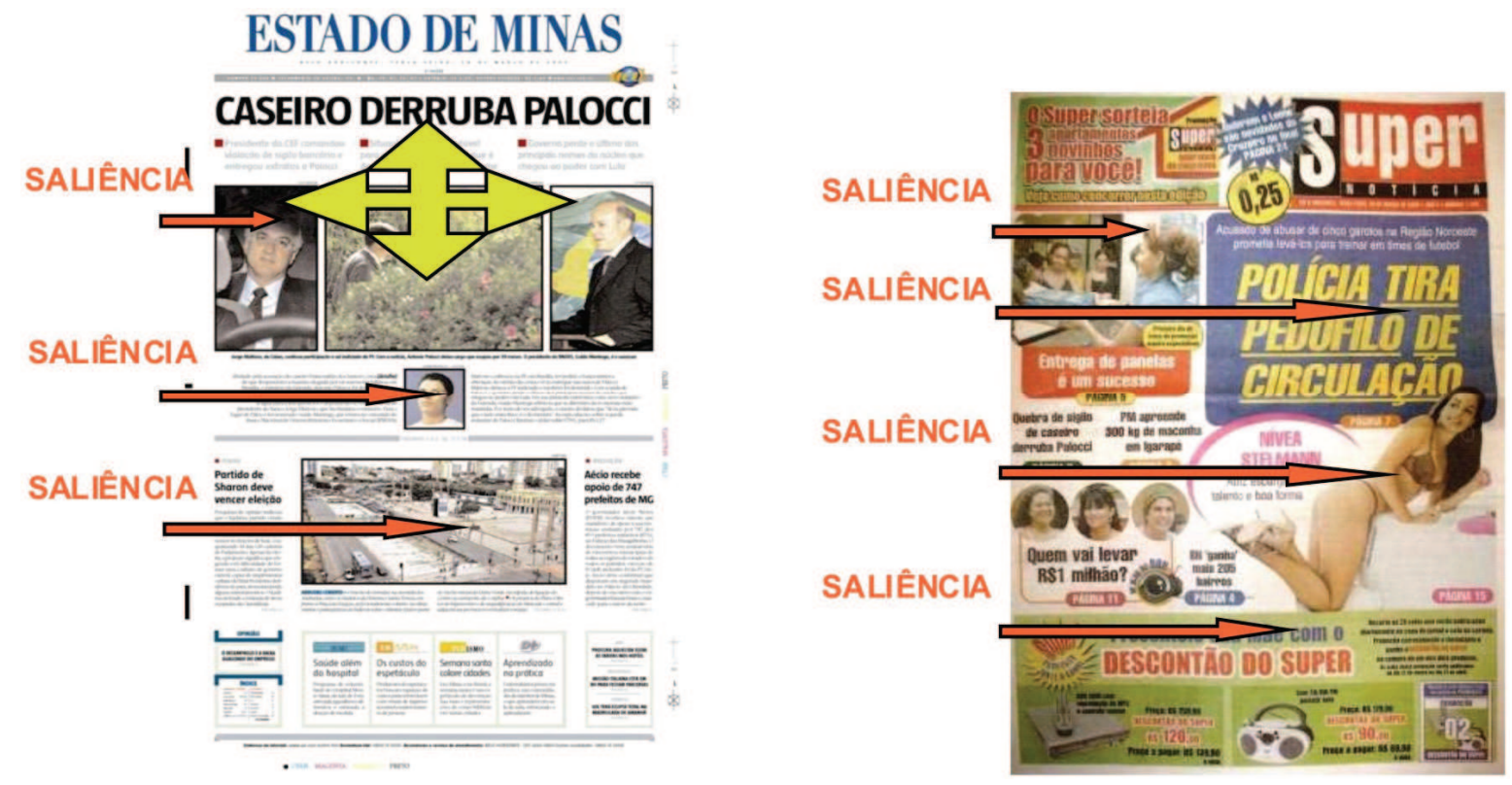

Figura 4 - Primeira página dos jornais Estado de Minas e Super Notícia - análise sob o enfoque dos recursos de saliência.

\section{Emolduramento}

A primeira página analisada do Estado de Minas possui um layout de diagramação predominantemente horizontal, mostrando-se semelhante aos formatos tradicionais de jornais, dado o equilíbrio dos espaços em branco entre textos de chamadas e imagens. Nota-se uma forte desconexão entre Ideal (pauta nacional) e Real (pauta local e estadual), devido ao fio cinzento de emolduramento que demarca tais domínios, priorizando, desse modo, o cenário político nacional.

A rima visual configurada pela tonalidade bege das linhas de emolduramento empregadas nas chamadas, nos cadernos especiais, na seção Opinião e no índice do jornal parece promover a conexão entre os elementos informacionais pertencentes ao domínio do Real. Observa-se, ainda, que a rima visual formada pela cor azul empregada na fonte e em parte dos boxes referentes ao índice e à seção Opinião pode sugerir tanto a ideia de conexão entre ambos, como também a desconexão destes com os demais cadernos e chamadas da página, talvez por terem propósitos que não se resumem em informar, mas também em oferecer dados sobre a própria organização do jornal e apresentar interpretações e juízos de valor, respectivamente. 
Já no Super, há uma conexão entre os elementos, os quais não compõem necessariamente uma unidade de informação, mas sim um "mix" de variedades apresentadas ao leitor. Nesse sentido, vale assinalar o efeito de conexão configurado pela representação de Nívea Stelmann, em que parte de sua cabeça "invade" o domínio da chamada "Polícia tira pedófilo de circulação". A imagem da atriz parece concentrar a atenção do leitor em um primeiro momento para, em seguida, distribuí-la para as chamadas com as quais estabelece conexão, conforme sublinhado na análise dos recursos de saliência.

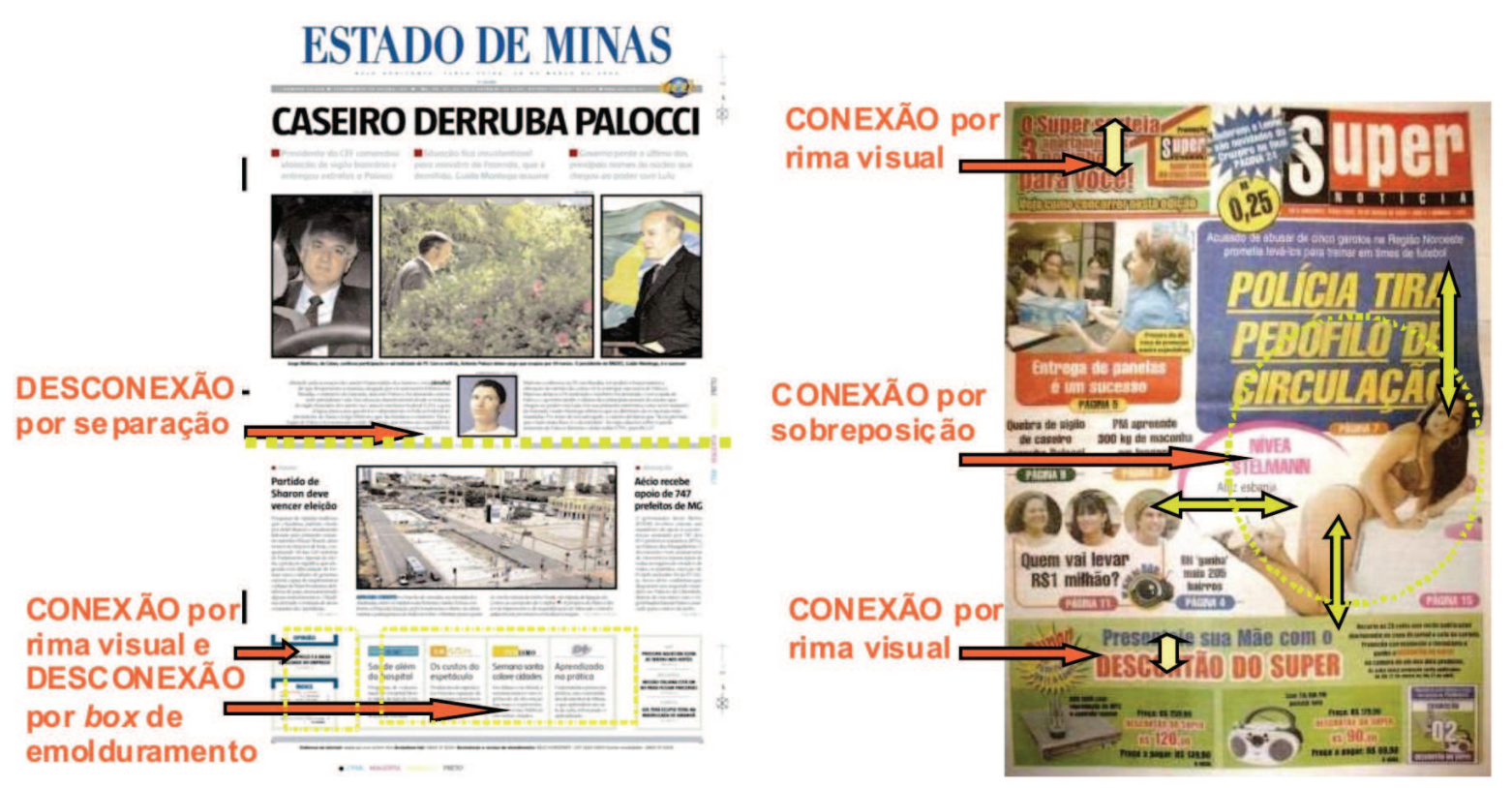

Figura 5 - Primeira página dos jornais Estado de Minas e Super Noticia - análise sob o enfoque dos recursos de emolduramento.

O uso das cores com o propósito de simbolizar algo nas chamadas, conectando seus elementos e reforçando-lhes a identidade, é observado em dois momentos. $\mathrm{O}$ primeiro diz respeito à chamada relativa a Nívea Stelmann, onde a presença da tonalidade rosa tanto na indicação da página da chamada em que é abordada quanto na fonte que indica o nome da atriz sugere a reprodução de um símbolo do feminino culturalmente construído (associado à cor rosa). O segundo momento refere-se às chamadas relativas às promoções, em que a rima visual estabelecida pelas tonalidades vermelho e verde confere unidade entre os elementos informacionais e identidade às ofertas de bens materiais e de consumo promovidas pelo Super Notícia.

CARVALHO - Os significados sociais construídos pela... 


\section{CONSIDERAÇÕES FINAIS}

Conforme pôde ser observado no decorrer do trabalho, é possível sugerir que o Estado de Minas prima pela formação social do leitor, seja por meio de uma diagramação discreta e sóbria, equilibrando cores, fontes, imagens e recursos de emolduramento, seja ao priorizar, por meio da saliência, as notícias relacionadas à política nacional e estadual, precisamente a representação da elite política detentora de poder, ao situá-las no domínio do Ideal.

Entretanto, é possível perceber que, com base na leitura visual da edição em questão, o jornal representou os atores sociais de forma tendenciosa, principalmente no que tange à saliência das fotos. A estrutura Ideal/Real hierarquiza as notícias e sugere a distinção entre as informações nacionais e estaduais; e o tríptico Dado/Mediador/Novo interpreta e avalia o evento principal. A orientação semiótica dominante é a Ideal, pois é a mais saliente e a que confere mais status e prestígio ao jornal. Nestes termos, a cobertura política nacional parecer receber prestígio e importância por parte do jornal. O domínio do Real, por sua vez, fica reservado aos acontecimentos locais e estaduais, caracterizados como informações mais práticas e voltadas para o cotidiano dos seus leitores. Além disso, atores sociais de baixo poder hegemônico parecem ser apresentados hierarquicamente como inferiores, como é o caso da representação do caseiro Francenildo.

A pluralidade de editorias apresentadas na primeira página do Estado de Minas, bem como o grau de desconexão e racionalidade, figurados entre as chamadas, possivelmente aponta para o perfil dos leitores do jornal, qual seja, as classes A e B, presumivelmente com mais poder aquisitivo e maior grau de instrução, o que os capacita a sistematizar e refletir sobre os fatos do mundo (BOURDIEU, 1991).

Em contrapartida, o entretenimento e a autopublicidade ocupam uma posição de destaque na primeira página do Super Notícia. Ademais, a composição analisada apresenta as informações de modo assistemático, com elevado grau de conexão e saturação entre elas, talvez reproduzindo o perfil dos "leitores em potencial" do tabloide 
(predominantemente pertencente à classe $\mathrm{C})^{16}$, que têm baixo poder aquisitivo e pouco nível de instrução e, por isso, teriam eventualmente maior dificuldade em organizar e sistematizar a realidade (BOURDIEU, 1991).

Com efeito, o mecanismo utilizado pelo jornal pode ser descrito da seguinte forma: enfatizam-se os sorteios e os produtos oferecidos pelas promoções, repete-se o enfoque dado às notícias e à significação dos elementos visuais representados, mantendo sua previsibilidade, a fim de tornar-se reconhecido e familiar ao leitor-consumidor. Em suma, pode-se dizer que o Super Notícia atribui extrema importância à sua autopublicidade, através de sorteios e promoções, fazendo do veículo informacional um passaporte para o consumo. Nesta linha, prioriza os faits divers, ao selecionar eventos relacionados ao entretenimento, ao mundo das celebridades, ao consumo, à violência e à "espetacularização da notícia"17.

A partir deste estudo de caso, foi possível confirmar a aplicabilidade do referencial teórico-metodológico da Gramática Visual na análise da primeira página de jornais, pois conseguiu-se, no decorrer deste trabalho, atingir o objetivo visado de compreender, através das estruturas de representação que compõem o layout do corpus, os significados das práticas sociais engendradas pelos modos semióticos configurados em sua primeira página e suas respectivas contribuições na orientação e formação do leitor de cada um dos jornais.

\section{REFERÊNCIAS}

ARBEX JR., J. Showrnalismo: a notícia como espetáculo. São Paulo: Editora Casa Amarela, 2001.

BELL, A. The language of news media. Oxford: Blackwell, 1991.

BOURDIEU, P. Language and symbolic power. Cambridge: Harvard University Press, 1991.

\footnotetext{
${ }^{16}$ Estudos Marplan $-4^{\circ}$ trimestre de 2005.

${ }^{17}$ Para mais esclarecimentos acerca do conceito, ver Arbex Jr. (2001) e Debord (1997).

CARVALHO - Os significados sociais construídos pela...
} 
CARVALHO, F. F. Os significados composicionais e a formação de subjetividades na primeira página de jornais mineiros: um estudo de caso à luz da gramática do design visual. 2007. 123f. Dissertação (Mestrado em Estudos Linguísticos) - Faculdade de Letras, Universidade Federal de Minas Gerais, Belo Horizonte.

CARRATO, A. Imprensa mineira, um monopólio próximo ao fim. In: MOUILLAUD, M., PORTO, S. D. (Org.). O Jornal: da forma ao sentido. 2. ed. Brasília: Editora da UnB, 2002.

CASTRO, J. Tabloide destrona o Estado de Minas. Observatório da Imprensa, 26 fev. 2006. Disponível em $<$ http://www.observatoriodaimprensa.com.br/artigos.asp?cod=370IMQ001 $>$. Acesso em 18 jan. 2007.

COLLARO, A. C. Projeto gráfico: teoria e prática da diagramação. São Paulo: Summus, 1987.

DEBORD, G. A sociedade do espetáculo. Rio de Janeiro: Contraponto, 1997.

DIAS, A. R. F. O discurso da violência: as marcas da oralidade no jornalismo popular. São Paulo: Cortez, 2003.

FERREIRA, S. N.; GIL, G. Understanding text-image relationships in newsweek cover stories: A study of multimodal meaning-making. 2003. $168 \mathrm{f}$. Dissertação (Mestrado em Inglês e Literatura Correspondente) - Faculdade de Letras, Universidade Federal de Santa Catarina, Florianópolis.

FERREIRA JÚNIOR, J. Capas de jornal: a primeira imagem e o espaço gráfico visual. São Paulo: Editora SENAC, 2003.

FOWLER, R. Language in the news: discourse and ideology in the press. London ad New York, 1991.

GARRET, P., BELL, A. Approaches to media discourse. USA: Blackwell Publishers, 1998.

HALLIDAY, M.A.K. Language as social semiotic. London: Edward Arnold, 1978.

HALLIDAY, M.A.K. An introduction to functional grammar. 2. ed. London: Edward Arnold, 1994.

HODGE, R., KRESS, G. Social semiotics. London: Polity Press, 1988.

JEWITT, C. The Routledge handbook of multimodal analysis. London: Routledge, 2009. 
JEWITT, C.; OYAMA, R. Visual meaning: a social semiotic approach. In: van LEEUWEN, T.; JEWITT, C. Handbook of visual analysis. London: SAGE Publications, 2001.

KRESS, G. Literacy in the new media age. London and New York: Routledge, 2003.

KRESS, G. Representational Resources and the production of subjectivity. In: CALDAS-COULTHARD, C. M., COULTHARD, M. Texts and practices: readings in critical discourse analysis. London: Routledge, 1996.

KRESS, G. Multimodality: a social semiotic approach to communication. London \& New York: Routledge, 2010.

KRESS, G.; van LEEUWEN, T. Reading images: the grammar of visual design. London and New York: Routledge, 1996.

KRESS, G.; VAN LEEUWEN, T. Front Pages: (The critical) analysis of newspaper layout. In: BELL, A, GARRETT, P. (Eds.). Approaches to media discourse. Oxford: Blackwell, 1998.

KRESS, G.; LEITE-GARCIA, R., van LEEUWEN, T. Semiótica discursiva. In: van DIJK, T. A. EI discurso como estructura y proceso. Barcelona: Gedisa Editorial, 2000.

KRESS, G.; VAN LEEUWEN, T. Multimodal discourse: The modes and media of contemporary communication. London: Arnold, 2001.

KRESS, G.; van LEEUWEN, T. Reading images: the grammar of visual design. 2.ed. London and New York: Routledge, 2006.

MACHIN, D. Introduction to multimodal analysis. London: Hodder Arnold, 2007.

SOUZA, R. S. R. Algo de estranho na imprensa mineira. Observatório da Imprensa, 20 jun. 2005. Disponível em

$<$ http://www.observatoriodaimprensa.com.br/artigos.asp?cod=334IMQ011 $>$. Acesso em 18 jan. 2007.

VAN LEEUWEN, T. Introducing social semiotics. London; New York: Routledge, 2005.

Recebido em 19/09/08. Aprovado em 15/03/10. 
Title: The social meanings constructed by the layout of the front page of Brazilian newspapers

Abstract: This paper aims at analyzing the social meanings constructed through the layout of the front page of two Brazilian newspapers: Estado de Minas and Super Noticia. The theoretical framework adopted is Social Semiotics (HODGE \& KRESS, 1988; JEWITT, 2009; KRESS, 2010; KRESS \& VAN LEEUWEN, 1996, 2001, 2006; $M A C H I N, 2007)$, which conceive the texts from a multimodal perspective, covering the analysis of all the semiotic resources used in a type of text in order to obtain full understanding of its meaning. The methodology is based on network systems concerning "compositional meanings", defined by Kress \& van Leeuwen (1996, 1998, 2006) as the way in which representational and interactive features are integrated to design the elements of the layout and give it coherence and unity of meaning through three interrelated systems: "informational value", "salience" and "framing". The results indicate that the layout of Estado de Minas seems to offer a semiotic structure oriented to the social and cultural development of the readers; however, it suggests biased representations of social actors from the realm of politics. On the other hand, the layout of Super Noticia presents a unsystematic semiotic structure, apparently familiarizing its readers with information oriented to consumption, sex and violence.

Keywords: Social semiotics; multimodality; press; front page. 